\title{
Evolving Roles of Outstanding School Heads in Meeting the Challenges of the New Normal: A Phenomenological Study
}

\author{
Dr. Merly J. Sarzoso', Dr. Marcial M. Bandoy¹, Dr. Albert A. Yazon', Consorcia S. Tan¹, Dr. \\ Lerma P. Buenvinida ${ }^{1}$ \\ ${ }^{1}$ Department of Education, Schools Division of Calamba City, Laguna State Polytechnic University, \\ Philippines
}

\begin{abstract}
The study mainly focused on determining the evolving roles of the outstanding school heads in meeting the challenges of the new normal. It also aimed to develop a compendium of best practices to help the school leaders in addressing the difficulties they are encountering in the new normal. This qualitative research utilized phenomenology as an approach. There are 10 outstanding school heads - participants who were chosen through purposive sampling by which the participants share common experiences. The researcher used validated semi-structured interview guide questions as the main instrument, and a one-on-one interview was conducted in order to obtain meaningful data. The data were transcribed and coded for the researcher to come up with the emerging themes. The themes that emerged from the testimonies of the participants were clustered into a superordinate theme: Plugged in surveillance, evince reciprocity, paradigmatic positive alacrity, and fondness of diversity. Moreover, a compendium of best practices was developed to provide opportunities and tools for the school leaders in addressing and meeting the challenges in the new normal in education. The results of the study can be used by the school heads in addressing the challenges that they are facing in different circumstances like this pandemic. Their roles are becoming broader and spiced up by some complications brought about by the need to be more responsive and able to maintain the quality characteristics of basic education services primarily wielded out by teachers and with the support of local stakeholders in these most trying times of pandemic. A compendium of best practices is necessary since it will serve as the guide of the school heads in providing solutions to the existing problems because of the pandemic, and at the same time, it will be their framework in replicating and adapting the best practices shared by the participants.
\end{abstract}

Keywords: challenges in the new normal, evolving roles, outstanding school heads, phenomenology

This is an open-access article under the CC-BY-NC license •

\section{INTRODUCTION}

Even though the education system faces the new normal, educators and school leaders must still show dedication and passion in the delivery of quality basic education to the learners since this is one of their roles which nowadays evolve into their primary role and also serves as their daily routine. This is one of the criteria to become outstanding educators as well as school heads - doing ordinary things extraordinary. Due to the global pandemic that we are experiencing now, educators must also change the ways in delivering their content and subject matter as the school heads need to change their ways in managing the schools, school heads need to create new paths, change into new directions which are some of the evolving roles they need to perform in this new normal in education. Schools are one of the most critical social organizations in charge of educating future generations, evaluating their behavior, and changing their beliefs and attitudes. When countries and cultures face crises and tribulations, schools bear the brunt of the responsibility and continue to be the most effective method for correcting concepts. In the present circumstances and the successive difficulties in the era of globalization and the development of the planet into a small village, schools' positions in fostering academic welfare and resolving intellectual differences encountered by students have become an acute necessity and a crucial need (Al-Sulaiman, 2016). This global pandemic revealed a major gap in Corresponding author Dr. Merly J. Sarzoso, sarsozomerly@gmail.com DOI: https://doi.org/10.31098/ijtaese.v3i2.663 
International Journal of Theory and Application in Elementary and Secondary School Education (IJTAESE), Vol. 3 (2), 91-100 Evolving Roles of Outstanding School Heads in Meeting the Challenges of the New Normal: A Phenomenological Study Dr. Merly J. Sarzoso, Dr. Marcial M. Bandoy, Dr. Albert A. Yazon, Consorcia S. Tan, Dr. Lerma P. Buenvinida

instructor readiness and instruction for emergency remote education, which includes using technology to ensure that students at a distance continue to learn (Trust and Whalen, 2020). One of its consequences is the requirement for strict physical separation, which is a critical intervention in preventing or mitigating the spread of the disease. The principles of Sulong Edukalidad include the protection of learners' health, safety, and well-being, as well as the prevention of the spread of COVID-19. They also include the maintenance of learning continuity through $\mathrm{K}$ to 12 curriculum adjustments, alignment of learning materials, deployment of multiple learning delivery modalities, and provision of corresponding training for teachers and school personnel (Department of Education, 2020). School leadership has been a focus in social policy in the current global educational change. It has a significant impact on teacher engagement and ability, which helps to improve the school environment (Pont, Nusche, and Moorman, 2018).

Meanwhile, the academic success of children is regarded as the primary goal of school reforms, which has been officially recognized. Many educational reform studies have shifted their emphasis to examining the relationship between leadership and student achievement in recent years (Harris, 2018). Different scholars have also agreed that the role of leadership is the most important factor influencing the effectiveness of a school and the academic achievement of its students (Gentilucci and Muto, 2017). A key finding of their research was that the job of school leadership is to create and maintain an environment that maximizes teachers' ability to teach and students' ability to learn. This is accomplished by focusing first on individuals and then on organizational structure and policies, and finally on the desired outcome of the transition, which is academic achievement. Furthermore, positive leadership has been shown to improve the school environment and the community by motivating teachers and students to achieve higher levels of academic achievement, according to research (Leithwood, Louis, Anderson, and Wahlstorm, 2014).

Numerous researchers, including myself, believe that the school principal is required to hold teachers and students accountable for their academic progress by developing commitments and a shared vision to motivate both teachers and students (Spillane 2016). In the twenty-first century, transparency as a modern educational phenomenon has gained traction. As a result, school principals face a variety of pressures and complexities in terms of their leadership style expectations and experience, which have a positive impact on student achievement (Gamage, Adams, and McCormack 2019). These difficulties have a strong impact on school administrators. According to Walker and Stott's (2020) research, principals and teachers are more likely to suffer feelings of disappointment, depression, and irritability. Staff attrition is higher as a result of these stress-related issues, and many principals have lost their positions as a result. As a counterpoint to this argument, a study conducted by Harris (2018) found that the old organizational structure of schooling does not meet the needs of learners in the twenty-first century. In order to address this issue, new schooling models that emphasize teamwork, networking, and multi-agency leadership are gaining traction.

The Role Theory by Ralph Turner deals with the organization of social behavior at both the individual and the collective levels. Individual behavior in social contexts is organized and acquires meaning in terms of roles. Work responsibilities in organizations are organized into roles, as is participation in groups and in society. Consequently, role theory is one key element in understanding the relationships among the micro-, macro-, and intermediate levels of society.

The situational theory of leadership suggests that no single leadership style is best. Instead, it depends on which type of leadership and strategies are best suited to the task. According to this theory, the most effective leaders are those that are able to adapt their style to the situation and look at cues such as the type of task, the nature of the group, and other factors that might contribute to getting the job done.

The study will investigate the evolving roles of outstanding school heads in meeting the challenges of the new normal in the educational system. Through the results of the present study, the researcher has crafted a compendium of best practices for the school in this new normal. The central question of the study is: What is the essence of the lived experiences of the outstanding school heads regarding their roles in meeting the challenges of the new normal in education?

The corollary questions are: How do the outstanding school heads describe their lived experiences as regards their roles in meeting the challenges of the new normal in education? What themes emerge from the testimonies shared by the outstanding school heads as to their evolving roles in meeting the challenges of the new normal in education? Based on the findings and reflections, what compendium of best practices 
regarding the evolving roles of the outstanding school heads can be offered to help the school heads about the challenges of the new normal in education?

\section{Objectives of The Study}

The study aimed to determine the evolving roles of the outstanding school heads in meeting the challenges in the new normal in education and craft a compendium of best practices that can be used and shared to the school heads to serve as their guide in dealing with the difficulties they met in the new normal.

\section{MATERIALS AND METHOD}

The study utilized qualitative research. This approach is used when a researcher is "interested in drawing out relationships and patterns of gathered data to gain a deeper understanding of a phenomenon" (Research in Daily Life 1, 2016). These studies are discovery-oriented; the findings are not predetermined because the variables are not manipulated; rather, the research is emergent in design, and the findings are not predetermined. As a result of the ongoing data collection and inductive data analysis, research questions and data collection procedures or protocols may be revised or altered throughout the course of the study (Creswell, 2007). When it comes to exploring and understanding the lived experiences of outstanding school heads about their evolving roles in addressing the challenges of the new normal in education, phenomenological research is the approach that is most appropriate for the purpose of the study.

The researchers used a non-probability purposive sampling design for this investigation. It was necessary to contact those who met the eligibility requirements in order to inform them of the study's purpose and obtain their consent to participate. In this study, the saturation of information, defined as the point at which repeated confirmation of previously collected data occurred, was used to determine the size of the sample to be used. Pre-interviews were conducted by the researcher in order to select the participants for the study. With the initial interview, the researchers hoped to determine whether or not potential participants would be willing and open to taking part in the study.

The study was divided into three main stages. The first stage is Phenomenological Reduction which requires participation from the researcher and the respondents. After interviewing the respondents, the researcher will describe individual experiences through textual language. Researchers were considered the external object related to their experiences. At the same time, the researcher was also considered the internal act of consciousness, which refers to the rhythm and relationship between phenomenon and self. The researcher was eliminated all elements that are not directly within conscious experience. In this section, the researcher has used the principle of bracketing (Gearing, 2004) to address two negative procedures that Husserl (1939/1954) discusses: (a) the epoché of natural sciences -return (from theories) to the things themselves (avoiding explanations) and (b) the epoché of the natural attitude. The researcher assured that the researcher was aware of presumptions and presuppositions. The researcher was concentrated on original phenomena the way it manifests rather involving in it.

The second stage is the imaginative variation by which involves validation of the respondent's answers. The researcher validated the responses of the respondents in the one-on-one that was conducted through the observation method. Afterward, the researcher removed unnecessary features of the responses by finding a possible meaning of the phenomenon. Also, in this stage, the researcher identified and listed the emerging themes.

The last stage is intuitive integration. In this stage, the researcher has created narratives for each respondent, including textural describing "what" occurred and describing "how" it occurred. The researcher listed the meaning units for each respondent. After that, the researcher created meaning units common to all respondents and created composite textural and structural descriptions based on these shared meaning units. Moreover, in this stage, the researcher identified the essence of the phenomenon.

The present study required a relatively homogeneous group of participants. The participants have experienced the same phenomenon. The selected participants in this study have significant and meaningful experiences of the phenomenon investigated.

The participants of this research study consist of 10 outstanding school heads who are awarded as Gawad Patnugot Most Outstanding School Head at the elementary or secondary level. The participants also showcase the evolving roles of school heads which are brought by the new normal in the education system. 
In gathering pertinent information, the researcher used interview guide questions to direct the flow of discussions with the respondents. The researcher prepared ten questions for the respondents. During these questions, the participants were asked to reflect on the entire discussion and then to express their positions or opinions on topics that were important to the researcher during the discussion. The researcher used openended questions, and the questions ensured that the participants were actively involved in the research. The open-ended questions were divided into three - opening questions, key questions, and ending questions. It is the goal of the opening questions to introduce participants to the discussion topic and to make them feel comfortable sharing their opinions with the rest of the group. The key questions are explored in greater depth, as are the discussion topic and the opinions of the participants. This is a closing question that asks participants to reflect on the entire discussion and then to express their positions or opinions on topics that are of primary importance to the researcher.

A letter of consent was secured from the Schools Division Superintendents of Cabuyao City, Sta Rosa City, Biñan City, San Pablo City, and Calamba City. Thereafter, the Focus Group Discussion was scheduled with the school heads. The researcher was prepared the guide questions, recording gadgets, writing materials before the researcher facilitated the interview. An assistant to scribe the discussion asked to engage. The recorded interviews were transcribed and reconciled with the written account. Afterward, the researcher proceeds with the encoding of the verbatim transcription, tabulation of data, and qualitative data analysis, then arrives at emerging themes.

The researcher followed ethical guidelines stipulated in LSPU Research Manual. The researcher explained to the respondents the significance and objectives of the study. The confidentiality of the information shared by the participants was secured. The authors of literature and studies used in establishing the rationale, background of the study and to support the findings of the study were given proper citation. At the time of data gathering, she asked first the willingness of the participants by sending them a letter of consent and

securing that they agreed in the terms and agreement stipulated in the letter before formally inviting them to a one-on-one interview. The researcher also avoided giving opposing comments on respondents' views or opinions on the matter of topics that arose in the discussion. She prevented herself from asking the participants questions or follow-up inquiries that led the respondents against the truthfulness of his/her experience. The researcher observed sensitiveness on the diverse challenges encountered by the outstanding school heads in terms of their evolving roles in addressing the new normal. The line of questioning was safe from casting any insult on the abilities of the teachers and with any discriminatory words. The responses of the participants were transcribed and coded properly, following the steps in phenomenological study data analysis.

The qualitative method used in this study was theme-centered analysis, which is a term that is commonly heard. The term "thematic analysis" refers to a specific theme-centered approach to analysis. One of the advantages of this type of analysis is that it allows for a great deal of theoretical flexibility. Thematic analysis is carried out by categorizing and coding the data. When you code, you combine data for themes, ideas, and categories. Then you mark up similar passages of text with a code label so that they can be retrieved at a later time for further comparison and analysis. It is easier to search for, compare, and identify patterns when the data has been coded (Alase, 2016).

\section{Trustworthiness}

In hopes of persuading readers that the findings are worth paying attention to, this study may be judged by the trustworthiness criteria as described by Lincoln and Guba as cited by Heindel (2014), which are (1) Truth value; (2) Applicability; (3) Consistency; and (4) Neutrality.

\section{Credibility}

To demonstrate "true value," the qualitative researcher must show that his or her representation of "the truth" (since findings and interpretations are constructions of the qualitative researcher) has been 
represented adequately and that they are credible. Credibility, then, is the qualitative researcher's equivalent of internal validity (Lincoln and Guba, 1985).

\section{Transferability}

In contrast to quantitative inquiry, generalizability (or external validity) is demonstrated by showing that the data have been collected from a sample that is somehow representative of the population to which generalization is sought (Lincoln and Guba, 1982). However, qualitative researchers downplay the notion of generalization because they doubt whether generalizations can be made about human behavior, given the passage of time and changing contexts (Lincoln and Guba, 1982).

\section{Dependability}

In quantitative analysis, reliability or dependability is described as the ability to reproduce or repeat a study under the same conditions in a different location and at a different time. If there are differences between the two repetitions, the discrepancy is attributed to unreliability or mistake (Lincoln and Guba, 1982). In qualitative research, however, research designs are emergent, and changes are made consciously. Also, emergent designs prevent an exact duplication of a study, especially given that a second inquirer may choose a different path from the same data. The qualitative researcher defines "dependability" to mean "stability" after discounting such conscious and unpredictable changes (albeit rational and logical) in research design (Lincoln and Guba, 1982).

\section{Confirmability}

As Scriven (1972) points out, the intersubjective agreement is typically used to judge objectivity. What several people experience is objective, but what a single person experience is subjective; Scriven calls this the "quantitative" sense of objectivity.

In gathering pertinent information, the researcher used interview guide questions to direct the flow of discussions with the respondents. The researcher prepared ten questions for the respondents. These questions asked the participants to reflect on the entire discussion and then offered their positions or opinions on topics of central importance to the researcher. The researcher used open-ended questions, and the questions ensured the involvement of the participants. The open-ended questions were divided into three opening questions, key questions, and ending questions. Opening questions are intended to introduce participants to the discussion topic and make them feel comfortable sharing their opinion with the group. Key questions are delved further into the discussion topic and participants' opinions. The ending question is a question that asks the participants to reflect on the entire discussion and then offer their positions or opinions on topics of central importance to the researcher.

\section{Opening Questions}

1. How are you feeling today?

2. How long are you in the school as principal?

\section{Key Questions}

3. Now that we are in the so-called New Normal in Education: describe your experiences as a school head?

4. Did you experience any difficulties in managing the school, the teachers, and other stakeholders in the new normal? (If yes, what were they?)

5. Describe how do you handle all the challenges you encountered brought by this global pandemic?

6. How would you compare your roles as a school head before (traditional or face-to-face) and at present (in the new normal)?

7. How do you prepare for this kind of shift in your roles as a school head?

8. What specific recommendations do you have for other school heads in meeting the challenges of the new normal in education?

\section{Ending Question}


9. Is there anything else you would like to add?

\section{FINDINGS AND DISCUSSION}

The participants of the study are all identified outstanding school heads from the City Schools Divisions of Calamba, Cabuyao, Binan, Santa Rosa, San Pablo, and Division of Laguna Province. The testimonies of the participants described that they experienced difficulty in handling situations in the new normal, but they are making all the possible ways to provide quality education to the learners. It implies that there are important roles to maintain the attractiveness of a school's performance. School administrators serve as the link between educational officials, teachers, students, and communities. When the heart fails, the whole system fails, just as it does in our bodies. School administrators have been under a lot of pressure to bring together an emergency response to education in the event of a pandemic. They need more time and resources in times of crisis than ever before to focus on the immediate challenges.

The testimonies of the participants described that they experienced a lot of difficulties from teachers, parents, resources, community, and other factors specified in the new setup of the educational system. These difficulties are the same problems they encountered during the traditional way of education but because of the global pandemic, the burden doubles because of the restrictions and limited mobility due to the COVID19 pandemic. In other words, one of the most frustrating things that principals have to deal with is a lack of parental involvement in the institution's efforts to improve students' academic achievement. Parents must also take responsibility for their children's poor academic performance. Making real-time status updates for activities, meetings, grades, fee collection, attendance, and discipline available via web and mobile devices will strengthen teacher-parent relationships and close the achievement gap. A significant amount of time and effort is expended by principals and their staff in developing relationships with students, teachers, and other members of the staff. The testimonies of the participants described that they are making ways to provide solutions to the existing difficulties and challenges brought by the global pandemic. They are all utilizing and maximizing all possible means to cater all the needs of the school in general. They are all seeking partnership and linkages from the parents, community, private organizations and individuals, and other stakeholders to help them in addressing and providing solutions to those encountered challenges and difficulties.

According to this interpretation, the COVID-19 crisis has had an unexpected and dramatic impact on the roles of school administrators. A clear path forward is impossible in this situation due to the extraordinary nature of the situation. School leaders are analogous to actors in a play whose plot, script, and costumes have all been changed in the middle of the performance and who must improvise in order to fit into their new role on the stage. There are occasions when school administrators must wait to listen to elected officials, system leaders, and first responders. The testimonies of the participants described that their roles as school heads are just the same, but the manner of doing it becomes different. Before, they were used to performing almost all their tasks physically and on a face-to-face basis. But because of the new setup, they perform their tasks virtually and online.It implies that, in a crisis, leadership should be collaborative, but it should also strive to be hierarchical in a sensible way. There are times when school leaders must be patient and listen to the advice of government officials, system-level administrators, and first responders. The testimonies of the participants described that their roles as school heads are doing all the possible ways just to prepare themselves, particularly on their roles in the new normal.

The findings suggest that theoretical knowledge is critical because it serves as the basis for any ability and introduces the learner to the subject. Practical learning, on the other hand, must be thoroughly combined with theoretical knowledge since it enables learners to apply theoretical knowledge in real-life situations and delve deeper into the topic. The testimonies of the participants described that as head of the school and as the one who will be the role model for others, they need to show and act positively to all the situations they are facing. They need to be stronger since they are the ones who will serve as the source of strength for the schoolteachers and personnel. They must also be more considerate than they were previously due to a variety of factors, including the health and safety of all teachers and school personnel. The findings suggest that effective teachers identify the academic needs of their students through the use of data such as reading inventories and other assessment tools. Data is used in a similar way by effective principals when determining areas of need for staff development activities. 
The themes that emerged from the testimonies of the participants were clustered into a superordinate theme: Plugged in surveillance, evince reciprocity, paradigmatic positive alacrity, and fondness of diversity.

\section{Plugged in Surveillance}

The continuity aspect of both monitoring and evaluation, which cannot be divided into watertight compartments, would be relevant to this analytical framework and would be included in the discussion below. Activities in the initial phases of monitoring and evaluation are more concerned with inputs and outputs, as well as the timeliness of those outputs, and then the process progressively turns in more impact data and becomes more concerned with impact evaluation, with special studies being added as needed.

\section{Evince Reciprocity}

Schools are well-planned, well-organized, and well-established institutions that assist citizens in socializing, improving their economic competitiveness, recognizing and realizing themselves, and adopting national policies. In terms of personal and social growth, the mission that schools are responsible for is critical. Schools are essential for society because they are the most productive, tangible, and practical component of the educational system.

\section{Paradigmatic Positive Alacrity}

The administrator keeps his eyes wide open to lead with optimism. She or he does not diminish, avoid, or sugarcoat a scenario but rather accepts the facts, no matter how messy or serious they are. An optimist is realistic about the present situation but chooses optimism on purpose. But this isn't all wishful thinking. It's a way of thinking that confronts problems head-on and sees them as opportunities.

\section{The fondness of Diversity}

For the vast majority of us, the school year has come to an end. Throughout the school year, there was a frenzy of activity as the schools administered standardized tests, planned transition activities for incoming and departing students, and completed all of the paperwork necessary to bring the school year to a close. Members of the team were pleased with yet another successful year. Teachers were giddy with excitement as they discussed their summer plans and reorganized their classrooms in preparation for summer cleaning. The building became noticeably quieter all of a sudden. However, despite all of the sense of completion that the end of a school year brings, the job of a principal does not come to an end.

The study necessitates an action plan based on the findings of the study focusing on the replication and adoption of the best practices of the outstanding school heads about their evolving roles in addressing the challenges encountered in the new normal in education. This compendium of best practices will provide a localized guide for each school head regarding the evolving roles in addressing the difficulties encountered, most especially in times of crisis like this pandemic.

\section{CONCLUSION}

The following are the issues and implications drawn by the researcher based on the consolidated findings of the study: (1) That participants are recognized as outstanding school division superintendents in their respective school division offices. There were numerous problems and difficulties they faced as a result of the pandemic. In these most trying times of pandemic, their roles are becoming broader and spiced up by some complications brought on by the need to be more responsive and capable of maintaining the quality characteristics of basic education services primarily wielded by teachers and with the support of local stakeholders. (2) That the participants' personal testimonies formed four mutually exclusive superordinate themes out of their various claimed evolving roles, which are worth considering when addressing the challenges and difficulties inherent in the current state of education in the new normal. $\quad$ (3) That a compendium of best practices is necessary because it will guide school leaders in addressing existing problems caused by the pandemic while also serving as a framework for replicating and adapting the best practices shared by participants.

On the other hand, based on the findings of the study, the following recommendations are offered: The Department of Education may offer various programs to prepare school administrators for any 
difficulties that may arise in the classroom. (2) The school's head of school may develop an effective plan to address the challenges they will face. (3) School officials may wish to consider the compilation of best practices highlighting the evolving roles of school leaders in addressing the challenges inherent in the new normal of education. (4) Future researchers may conduct a phenomenological study using a similar methodology to the current study, but with gender and location-based variation in candidate participation.

\section{Reflexivity Statement}

The researcher has come up with the following reflections based on the findings of the study that the evolving roles and best practices of the outstanding schools in the new normal help them a lot to become successful in every challenge they encounter. Experiences, either good or bad, make them much better persons of today since they learn from those experiences in managing their schools. The regular monitoring/ virtual monitoring of outstanding school to teachers and learners- online or modular classes help the school heads to know and provide the necessary and appropriate assistance to the teachers. In that way, teachers are able to improve their teaching style and strategy that lead to the development of the skills and ability of the students in distance learning. Every day is a challenging day for the outstanding school heads since they come across different people with different attitudes and different issues to solve. Dealing with the new face of education today makes them much stronger and more determined. They overcome those challenges by managing the school with a heart and being optimistic. There are no necessary characteristics or qualities to be outstanding school heads. Having a heart for the teachers, learners, stakeholders, and people around you and loving and enjoying what you are doing is enough to come up with the best accomplishments. The today situation of the new normal in education, school heads alone cannot accomplish all the tasks. They need the involvement of all teachers, stakeholders, and parents in the delivery of basic quality education to the learners. That the outstanding school heads have not expected any rewards, they are humble school leaders and educators who simply work not for any reward but for their schools. The compendium of best practices of the outstanding school heads is necessary to share with other school heads and educators to help them in managing their schools too.

\section{REFERENCES}

Ahmad, M. A., \& Dammas, A. H. (2018a). The Role of School Administrations and Educational Curricula in Promoting the Intellectual Security of Students. Journal of Education and Learning (EduLearn), 12(1), 8490. https://doi.org/10.11591/edulearn.v12i1.6635

American School Counselor Association. (2018). School counselor competencies. ASCA School Counselor, 45(6), 64-72.

Armstrong, S. A., MacDonald, J. H., \& Stillo, S. (2018). School counselors and principals: Different perceptions of relationship, leadership, and training. Journal of School Counseling, 8, 1-27.

Barth, R. (2018). Improving schools from within. San Francisco, CA: JosseyBass. Barth, R. (2019). Learning by heart. San Francisco, CA: Jossey-Bass.

Begley, P., \& Slater, C. (Eds.). (2018). School Leadership in Canada (2nd ed.). Hillsdale, Ontario: Paul Begley and Associates.

Browne-Ferrigno, T., \& Muth, R. (2019). Leadership mentoring in clinical practice: Role socialization, professional development, and capacity building. Educational Administration Quarterly, 468-494.

Cash, J. (2017). What good leaders do. Thrust for Educational Leadership, 27, 22- 25.

Carnine, L., Denny, G., Hewitt, P., \& Pijanowski, K. (2018, May). The status of school leadership in Arkansas. Fayetteville, AR: Research Advocacy Network.

Clark, A. (2019). The importance of school principals. Parent News. Retrieved December 1, 2019 from the W orld Wide Web: http://npin.org/pnews/1999/pnew599/int599d.html

Crawford, N. (2015). Editorial---roles, responsibilities, relationships: a new metaphor. Challenge in Educational Administration, 32 (2), 4-6. 
Dahir, C. A., Burnham, J. J., Stone, C. B., \& Cobb, N. (2017). Principals as partners: Counselors as collaborators. NASSP Bulletin, 94(4), 286-305.

Day, C. (2017). The passion of successful leadership. School Leadership and Management, 425-437.

Dufour, R. \& Eaker, R. (2018). Professional learning communities at work. Bloomington, IN: National Educational Service.161

Fullan, M. (2018, April). Leadership for the 21st century: Breaking the bonds of. Educational Leadership, 55(7), 6-10.

Fullan, M. (2019). Education and change. The Canadian School Executive, Vol. No.7, 29-30

Gamage, A. \& Mccormak, A. (2019). How Does a School Leaders' Role Influence Student Achievements? Review of Research Findings and Best Practice. International Journal of Educational Leadership Preparation, 4(2), 1-16. http://cnx.org/content/m19751/1.2/

Gentilucci, J. \& Muto, K. (2017). Principals' Influence on Academic Achievement: The Student Perspective. The National Association of Secondary School Principals, Bulletin Sep. 2017. http://doi.org/10.1177/0192636507303738

Guba, E. G., \& Lincoln, Y. S. (1982). Epistemological and methodological bases of naturalistic inquiry. Educational Communication \& Technology Journal, 30(4), 233-252. https://psycnet.apa.org/record/198326960-001

Gurr, D. (2016). On conceptualizing school leadership: time to abandon transformational leadership? Leading and Managing, 2 (3), 221-239.

Harris, A. (2018). Distributed Leadership: Developing Tomorrow's Leaders, Routledge, London. http://doi.org/10.4324/9780203607909

Harvey, T., \& Donaldson, G. (2018). Professional vitality: Do you, have it? Principal, 83(1), 30-33.

Hawkins, R. (2019). The Vice-Principalship: Preparation for Leadership. Unpublished master's project, Universfor its Lethbridge, Lethbridge, Alberta, Canada.

Lashway, L. (2019). Who's in charge? The accountability challenges. NASSPPrincipal Leadership, 1 (3). Retrieved January 2, 2019, from the Wornormal with http://www.nassp.org/news/pl acntbly chlngl100.htm

Leithwood, K. \& Duke, D. (2017) Defining effective leadership for Connecticut's schools. Retrieved August 8, 2017, from the World Wide Web: http://www.schools.nLedu.au/forum/leithwood.pdf

Leithwood, K. (2018) Education accountability and school leadership. National College for School Leadership. Retrieved August 8, 2018, from the World Wide Web: http://www.ncsl.org.uk/index.dm ?pageID=ev auth leithwood\&textonly=true

Leithwood, K., Louis, S., Anderson, S. \& Wahlstrom, K. (2014). Review of Research, How Leadership Influences Students Learning from Leadership Project, Wallace Foundation, New York, NY. http://eric.ed.gov/ED485932

Lincoln, Y. S. \& Guba, E. G. (1985). Naturalistic inquiry. Beverly Hills, CA: Sage.

Lockwood, A. (2016). The changing role of principals: an interview with Philip Hallinger. New Leaders For Tomorrow's Schools. Retrieved November 25,2016, from the World Wide Web: http://www.ncrel.org/cscd/pubs/lead31131hallin.htm162

Lovely, S. (2017). Staffing the principalship: Finding, coaching, and mentoring school leaders. Alexandria, VA: Association for Curriculum and Development.

Michailides, M. \& Payne, L. (2018). Ten commandments for the 21 st century. Principal, 78 (2), 43-45.

Militello, M., \& Janson, C. (2017). Socially focused, situationally driven practice: A study of distributed leadership among school principals and counselors. Journal of School Leadership, 17, 409-442.

Murphy, J. (2016). Transformational change and the evolving role of the principal: Early empirical evidence. In K. L. J. Murphy, Reshaping the principalship: Insights from transformational reform efforts (pp. 20-53). Thousand Oaks, CA: Corwin Press. 
Peterson, K. (2019). The role of principals in successful school. Reform Talk. Retrieved November 25,2019, from the World Wide Web: $34 \mathrm{http} / /$ www . wcer. wisc.edu/ccvi/pubs/ReformTalklY eac 1 .. .lMac2019_Reform_Talk_3.htm

Pont, B., Nusche, D. \& Moorman, H. (2018). Improving School Leadership: Policy \& Practice, Volume 1 OECD Paris. https://www.oecd.org/edu/school/44374889.pdf

Richardson, J. (2019). Principals are "head learners" in successful schools. Results. Retrieved November 25,2019, from the World Wide Web: http://www.nsdc.org/library/results/res2-99rich.html

Sawchuck, S. (2018, September 8). Leadership gap seen in post-NCLB changes in U.S. teachers. Education Week. School-based management: changing roles for principals. (2016, October). [25 paragraphs]. Assessment of School-Based Management.

Scriven, Michael (1972): Objectivity and subjectivity in educational research. In: Thomas, L. G. (Ed.): Philosophical Redirection of Educational Research. Chicago: University of Chicago Press. Google Scholar

Sergiovanni, T. (2019). The lifeworld of leadership. San Francisco, CA: JosseyBass.

Sherry, L. (2016). Leithwood: transforming leadership. Retrieved July 11,2002, from the World Wide Web: http://www.cudenver.edll/ lsherrylinnovation/leithwood.html

Spillane, J. (2016). Distributed Leadership. San Francisco: Jossey-Bass.

Terry, P. (2019). Essential skills for principals. Thrust for Educational Leadership, 29 0), 28-32. The changing role of the principal. (2015). Retrieved November 19,2015, from the World Wide Web: http://www.awsp.org/chgrole2.htm.163

Townsend, D. (2016). Looking at the work of principals. Challenge in Educational Administration, 33 0),4-9.S Bureau of Labor Statistics. (2018). Occupational outlook handbook (Library Edition edition, Vol. Bulletin 2700). Washington, DC: U.S. Department of Labor.

Walker, P. \& Stott, K. (2020). Performance Improvement in Schools. A case Overdoes.Educational Management, Administration \& Leadership, 28(1), 63-76. http://www.ema.sagepub.com

Wesley, D. C. (2018). The administrator-counselor team. Principal Leadership, 6, 60-63

Wilkerson, K. (2017). School counselor reform and principals' priorities: A preliminary content analysis of the National Association for Secondary School Principals (NASSP) bulletin (1997-2017) informed by guiding documents of the American School Counselor Association (ASCA). Education, 131(2), 419-436.

Williams, R. L., \& Wehrman, J. D. (2017). Collaboration and confidentiality: Not a paradox but an understanding between principals and counselors. SAGE Publications, 94(2), 107-119.

Winter, P., Rinehart, J. S., \& Munoz, M. A. (2017). Principal recruitment: An empirical evaluation of a school district's internal pool of principal certified personnel. Journal of Personnel Evaluation in Education, 129-141. 